\title{
Necessidade do prévio esgotamento da instância administrativa para a caracterização do delito do art. 2, i, da Lei 8.137/90
}

Rodrigo José Mendes Antunes ${ }^{1}$

\begin{abstract}
Resumo
Trata-se de estudo por meio do qual se procura chamar a atenção da necessidade da prévia decisão definitiva das autoridades fazendárias no que concerne a exigibilidade do tributo, não só para a configuração dos crimes materiais do art. 10 da Lei 8.137/90, mas, também, para os crimes formais previstos no art. 20 da Lei dos Crimes Contra a Ordem Tributária, em específico o art. 2ㅇ, I, da lei em tela, visto que este contém a mesma natureza jurídica do art.10 já referido, exigindo-se que - no mínimo - para a instauração do inquérito policial ou ação penal, tenha a existência do tributo, o qual deverá ser "constituído" pela autoridade competente.
\end{abstract}

Palavras-Chave: Crime contra a Ordem Tributária; Lançamento definitivo administrativo; Natureza jurídica; Tributo; Elemento normativo.

\section{Introdução}

Após a publicação da Lei 8.137/90 (que define crimes contra a ordem tributária, econômica e contra as relações de consumo, e dá outras providências), iniciou-se a discussão no âmbito doutrinário e jurisprudencial, da necessidade ou não do esgotamento da instância administrativa para o início da ação penal e do inquérito policial, nos crimes definidos nos arts. 1으 da referida lei.

Com o advento do art. 83, da Lei 9.430/96, a qual exigia uma decisão final na esfera administrativa para que seja encaminhada representação fiscal ao Ministério Público, acirraram-se ainda mais os debates ${ }^{2}$.

No entanto, em dezembro de 2003 o Supremo Tribunal Federal decidiu, através do Habeas Corpus no $81.611^{3}$, que o crime do artigo 1으, da Lei $8.137 / 90$, de natureza material,

1 Advogado. Especialista em Direito Penal e Processo Penal da Universidade Estadual de Londrina.

2 DELMANTO, Fabio Machado de Almeida. O término do processo administrtivo-fiscal como condição da ação penal nos crimes contra a ordem tributária. Revista Brasileira de Ciências Criminais. São Paulo, n. 22, p. 6379, abr./jun. 1998. p. 63.

3 BRASIL. Supremo Tribunal Federal. Habeas-corpus n 81.611. Brasília, DF, 10 de dezembro de 2003. Relator: Min. Sepúlveda Pertence. Diário da Justiça da União, Brasília, 13 maio 2005. 
somente se consuma após o lançamento do crédito tributário, o qual ocorre apenas com o esgotamento da instância administrativa.

Em que pese seja o entendimento supra focado nos crimes de resultado (ou materiais) descritos nos incisos do art. 1ㅇ da lei em tela, induvidoso é que para a caracterização dos delitos dos arts. 1ㅇe e o da Lei 8.137/90, se faz necessário à existência no mínimo - do tributo devido.

Desse modo, no decorrer do presente artigo será analisado, à luz da doutrina e jurisprudência, a necessidade ou não, para a instauração do inquérito policial e da ação penal, da existência prévia do esgotamento da instância administrativa no que tange ao art. 2ำ, I, da Lei .8.137/90. Para realizar tal intento, serão abordadas questões relativas sobre a exata natureza jurídica do dispositivo supra, descrevendo-se sua estrita relação com o art. 10 da mesma lei, além da demonstração da influência do Direito Tributário nos crimes Contra a Ordem Tributária.

Assim, ainda que se trate de um tema pouco debatido na doutrina, será indagado no presente trabalho a imprescindibilidade do lançamento definitivo administrativo (elemento normativo do tipo do art. 2ํ, I, da lei 8.1367/90) para a configuração do crime em apreço, mesmo em se tratando de um delito formal.

\section{Observações preliminares}

\subsection{0 artigo 10 da Lei $8.137 / 90$}

Já se pode dizer que é pacífico tanto na doutrina como na jurisprudência o entendimento de que o crime do art. 1ํㅡ, da lei 8.137/90 é infração material, sendo necessário para a sua consumação, a efetiva supressão ou redução do tributo ${ }^{4}$.

Tal ilação é corroborada pelo magistério de Hugo de Brito Machado, ao consignar que "o crime previsto no art. 1ํ, da Lei 8.137/90, é crime de dano, que "somente se consuma com a supressão ou redução do tributo devido" ${ }^{5}$ (grifo nosso). Mesmo posicionamento de

\footnotetext{
4 BRASIL. Supremo Tribunal Federal. Habeas-corpus n 75.945-2-DF, 1ạ T., Brasília, DF, 2 dezembro de 1997. Relator: Min. Sepúlveda Pertence. Diário da Justiça da União, Brasília, 13 fev. 1998.

5 MACHADO, Hugo de Brito. Crimes contra a ordem tributária. In: MARTINS, Ives Granda (Coord.). Crimes contra a ordem tributária. São Paulo: Revista dos Tribunais, 1995. p. 114,
} 
Aristides Junqueira Alvarenga ${ }^{6}$, Rui Stoco $^{7}$, Nelson Bernardes de Souza ${ }^{8}$, Jose Carlos Tórtima ${ }^{9}$, Paulo José da Costa Jr. e Zelmo Denari ${ }^{10}$, dentre outros. Desse modo, se está pendente procedimento administrativo que discute débito tributário perante as autoridades fazendárias, não existe obrigação tributária exigível e, via de conseqüência, o tipo penal (art. 1을 $8.137 / 90$ ) configura-se após a exigibilidade do tributo.

Assim, é induvidoso que a "autoridade administrativa é a única exclusivamente competente para dizer da existência do tributo devido, conforme o art. 142, caput, do CTN, verbis:

Compete privativamente à autoridade administrativa constituir o crédito tributário pelo lançamento, assim entendido o procedimento administrativo tendente a verificar a ocorrência do fato gerador da obrigação correspondente, determinar a matéria tributável, calcular o montante do tributo devido, identificar o sujeito passivo e, sendo o caso, propor aplicação da penalidade cabível ${ }^{11}$

Diante disso, conforme já alegado, a Suprema Corte fixou o entendimento no HC 81.611 (Rel. Ministro Sepúlveda Pertence), e HC 83.414-1 (Rel. Ministro Joaquim Barbosa) ${ }^{12}$, de que se está pendente recurso administrativo que discute débito tributário perante as autoridades fazendárias, ainda não há crime, porquanto "tributo" é elemento normativo do tipo $^{13}$.

6 ALVARENGA, Aristides Junqueira. Crimes contra a ordem tributária. In: MARTINS, Ives Gandra (Coord.). Crimes contra a ordem tributária. São Paulo: Revista dos Tribunais, 1995. p. 50-51.

7 STOCO, Rui. Sonegação fiscal temas controvertidos. Revista dos Tribunais, São Paulo, v. 84, n. 713, p. 315327, mar. 1995. p. 326.

8 SOUZA, Nelson Bernardes de. Crimes contra a ordem tributária e processo administrativo. Revista Brasileira de Ciências Criminais. São Paulo, v. 5, n. 18, p. 93-101, abr./jun. 1997. p. 94.

9 TÓRTIMA, Jose Carlos. O objeto da tutela jurídica nos crimes fiscais. In: SALOMÃO, Heloisa Estelita (Coord.). Direito penal empresarial. São Paulo: Dialética, 2001. p. 147.

10 COSTA JR., Paulo José da; DENARI, Zelmo. Infrações tributárias e delitos fiscais. São Paulo: Saraiva, 1995. p. 107.

11 DELMANTO, 1998. p. 72.

12 BRASIL. Supremo Tribunal Federal. Habeas-corpus n 83.414-1, da 1a T., Brasília, DF, 2 de março de 2004. Relator: Min. Joaquim Barbosa. Diário da Justiça da União, Brasília, 23 abr. 2004.

13 Ibid. 


\subsection{Condição objetiva de punibilidade, condição de procedibilidade ou elemento normativo do tipo?}

A questão da necessidade do prévio exaurimento da instância administrativa pode levar a conclusão, de que se trata de mera condição de procedibilidade da ação penal. Tal entendimento não encontra respaldo lógico e legal, simplesmente porque a condição de procedibilidade concerne exclusivamente ao processo $^{14}$, não interferindo na tipicidade do delito. Ademais, por força do prescrito no artigo 15 da Lei 8.137/90, a ação nos crimes tributários será de iniciativa pública e incondicionada.

Noutra vertente, embora na ementa do Habeas Corpus no 81.611 restou decidido que o lançamento definitivo seja uma condição objetiva de punibilidade, tal entendimento não se mostra correto, pois conforme a observação de Walter Barbosa Bittar, nas chamadas condições objetivas de punibilidade, os elementos do fato punível estão localizados fora do tipo de injusto ${ }^{15}$, no que é corroborado por Marta Saad e Diogo Malan ao afirmarem que é incorreta a interpretação do Supremo Tribunal Federal no sentido do lançamento em questão consubstanciar condição objetiva de punibilidade, pois esta é por definição estranha aos elementos integrantes do tipo penal ${ }^{16}$.

O art. 1ํㅡ, caput da lei $8.137 / 90$ é claro ao prescrever "constitui crime contra a ordem tributária suprimir ou reduzir tributo, ou contribuição social e qualquer acessório, mediante as seguintes condutas:".

Ora, induvidoso que o lançamento definitivo administrativo se trata de um elemento normativo do tipo, pois somente com a declaração (pelas autoridades fazendárias) da existência de um crédito tributário é que se poderá falar em tributo, para - somente após tal declaração - pensarmos na existência do crime contra a ordem tributária, caso haja fraude (ou tentativa de fraude) na sua redução do crédito devido à fazenda pública.

14 MACHADO, Hugo de Brito. Estudos de direito penal tributário. São Paulo: Atlas, 2002. p. 154.

15 BITTAR, Walter Barbosa. As condições objetivas de punibilidade e as causas pessoais de exclusão da pena. Rio de Janeiro: Lúmen Júris, 2004. p. 72.

16 SAAD, Marta; MALAN, Diogo. Crimes contra a ordem tributária e a portaria SRF 326/05: novo esforço para restaurar a lógica do sistema. Boletim IBCCRIM, v. 13, n. 150, p. 11-12, maio 2005. p. 11. 
Nesse diapasão, Luiz Flávio Gomes leciona que elementares do delito são os “dados descritivos essenciais de cada crime. Seus dados nucleares" ${ }^{17}$ sem os quais não se identifica o delito. $^{18}$

Assim, não havendo dúvida quanto a sua condição nuclear do tipo penal do art. 1o e 2ㅇ, basta retirar a palavra "tributo" do tipo penal em apreço para concluir sua imprescindibilidade na norma primária ${ }^{19}$, sem o qual tal descrição típica fica vazia, sem conteúdo, não se podendo falar em crime tributário.

Ainda que possa parecer tal entendimento meramente acadêmico, considerando que a manifestação definitiva administrativa é um elemento normativo do tipo, pois será declarado a existência ou não de um tributo, é de importância ímpar esta conclusão para fundamentar a necessidade do prévio esgotamento da instância administrativa no que tange também aos crimes formais (que não são todos) do art. 2ำ, da Lei 8.137/90.

\section{0 art. 2ㅇ, caput da Lei 8.137/90 - natureza jurídica}

A descrição legal do caput do artigo 20 da Lei 8.137/90 é bastante sucinta quanto à conduta delituosa ao prescrever "Constitui crime da mesma natureza:".

Segundo o magistério de Andreas Eisele, o “art. 2o, caput, da Lei 8.137/90, resumese à indicação de que os crimes previstos em seus incisos possuem a mesma natureza dos crimes tipificados no art. 1ํ, ou seja, incluem-se entre os crimes contra a ordem tributária"20, sendo necessário, portanto, a redução ou supressão do tributo para a consumação do delito investigado ${ }^{21}$ (grifo nosso).

Antônio Corrêa assevera que a "afirmação 'crime da mesma natureza' refere-se logicamente ao do art. 1ㅇ da mesma lei, ou seja, os delitos contra a ordem tributária

\footnotetext{
17 GOMES, Luiz Flávio. Direito penal: parte geral: teoria constitucionalista do delito. São Paulo: Revista dos Tribunais, 2004. p. 79.

18 Ibid.

19 Segundo René Ariel Dotti são normas primárias as que "contém um imperativo de comando (fazer) ou imperativo de proibição (não fazer)". (DOTTI, René Ariel. Curso de direito penal: parte geral. 2. ed. Rio de Janeiro: Forense, 2004. p. 222).

20 EISELE, Andréas. Crimes contra a ordem tributária. São Paulo: Dialética, 1998. p. 147.

21 Ibid., p. 149.
} 
praticados por particulares, informados pelo dolo específico de sonegar tributos, contribuições ou obrigações equiparadas, com supressão total ou redução dos valores." ${ }^{22}$.

Por fim, no que diz respeito ao art. 2º, caput da Lei 8.137/90, é preciso analisar cada uma das hipóteses ali elencadas, já que, apesar da redação defeituosa do caput, a tutela penal do bem jurídico tutelado se faz de forma diversa em cada uma delas ${ }^{23}$, o que não descaracteriza a sua natureza jurídica de delito contra a ordem tributária.

\section{Conceito normativo do direito tributário}

Em face à íntima relação entre o Direito Tributário e o Direito Penal Tributário, é preciso ressaltar que "na Teoria Geral do Direito é inegável a distinção entre conceitos normativos, estabelecidos pela Ciência do Direito, e aqueles não normativos, ou descritivos, estabelecidos por outros setores do conhecimento humano"24.

Assim, baseado na doutrina de Karl Engisch, que distingue os conceitos normativos dos descritivos ${ }^{25}$, Paulo José da Costa Júnior afirma que "se a norma penal tributária, para tipificar uma conduta, se utiliza de conceitos normativos auridos do Direito Tributário, é esta disciplina que deverá ser consultada para precisar o alcance da norma. Em suma, é o Direito Tributário que deverá explicar e definir o que é "tributo", e "contribuição social" ou "sujeito passivo de obrigação", com vistas à tipificação do crime contra a ordem tributária" ${ }^{26}$ (grifo nosso).

Diante do exposto, reportando-se a tributo, e a contribuição social, na definição de tipo penal, o dispositivo criminal restou preenchido pelos dispositivos da legislação tributária dos quais resultam aqueles conceitos ${ }^{27}$.

22 CORRÊA, Antônio. Dos crimes contra a ordem tributária: comentários à Lei n. 8.137, de 27-12-1990. São Paulo: Saraiva, 1994. p. 154.

23 SALOMÃO, Heloisa Estellita. A tutela penal e as obrigações tributárias na Constituição Federal. São Paulo: Revista dos Tribunais, 2001. p. 210.

24 MACHADO, 2002. p. 158.

25 Ibid.

${ }^{26}$ COSTA JR.; DENARI, 1995. p. 101.

27 MACHADO, op. cit. p. 159. 


\subsection{0 tributo devido}

Esclarecida a influência do Direito Tributário no campo penal tributário, ainda que seja competência exclusiva da autoridade fazendária declarar o crédito tributário, para uma análise de um crime tributário, é preciso considerar o tributo no "contexto do tipo penal. Cuida-se o débito fiscal de dado essencial à tipicidade e, portanto, intrinsecamente ligado ao juízo da antijuridicidade (ou ilicitude)" ${ }^{28}$

Desse modo, para a configuração do crime do art. 20 da Lei 8.137/90 (como no artigo 1ㅇ) exige-se seja o tributo devido cuja supressão ou redução ${ }^{29}$ do crédito tributário decorra de qualquer modalidade descrita nos incisos do art. 20 da referida lei.

Neste diapasão, em qualquer hipótese, "o tipo penal, tanto o descrito no art. 1으, como o descrito no art. $2^{\circ}$, somente se configura se houver um tributo devido" 30 .

Segundo o magistério de Hugo de Brito Machado "[...] as diversas ações descritas nos incisos I e II do art. 2으, referem-se a tributo devido. Não havendo tributo devido, porque inocorrente o fato que, nos termos da lei aplicável, faz nascer à obrigação tributária correspondente, não se configura qualquer dos crimes em referência.." ${ }^{31}$ (grifo nosso)

Portanto, nesta mesma linha, destacou Agostinho Toffoli Tavolaro que "[...] em outras palavras, não se cogita, no tipo penal, somente de tributo ou contribuição, mas sim de tributo ou contribuição exigível, aquele que se reveste dos atributos de constitucionalidade e legalidade indispensáveis" ${ }^{32}$ (grifo nosso).

\section{A exegese do art. 2º, I da Lei 8.137/90}

Prescreve o art. 2ㅇ, I, da Lei 8.137/90 que constitui crime da mesma natureza (caput) "fazer declaração falsa ou omitir declaração sobre rendas, bens ou fatos, ou empregar outra fraude, para eximir-se, total ou parcialmente, de pagamento de tributo".

\footnotetext{
28 PITOMBO, Antônio Sergio Altieri de Moraes. O que não nos ensinaram sobre crime tributário. Boletim IBCCRIM, v. 12, n. 147, p. 4-5, fev. 2005. p. 4.

29 SCHOLZ, Leônidas Ribeiro. A criminalidade contra a ordem tributária no universo do direito econômico. Revista Brasileira de Ciências Criminais, São Paulo, n. 30, abr./jun. 2000. p. 101.

30 MACHADO, Hugo de Brito apud SCHOLZ, 2000, p.101.

31 MACHADO apud. SCHOLZ, op. cit. p. 101.

32 TAVOLARO, apud SCHOLZ, 2000. p. 101.
} 
De início, importa esclarecer que não pagar tributo, mesmo que seja devido, não é crime. O que tipifica o delito de sonegação fiscal é a intenção (dolo) do agente em não pagar o tributo mediante algum artifício fraudulento.

No que tange ao dispositivo supra, entende Andréas Eisele que "trata-se, na hipótese do art. 1으, caput, de crime progressivo, pois o agente pratica, na conduta naturalística, o fato previsto no art. 2으, I, mediante alguma das formas indicadas nos incisos

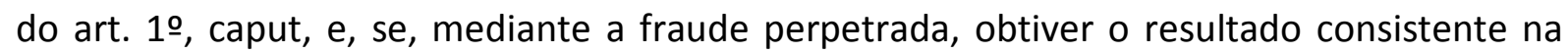
evasão fiscal, suprindo ou reduzindo tributo, praticará o crime material, definido no art. 1으, caput $^{\prime 33}$, concluindo que 0 art. $2^{\circ}$, I, representa uma modalidade tentada do art. $1^{\circ}$, caput, visto que não houve o resultado consistente na efetiva evasão tributária ${ }^{34}$.

Em que pese discorde a maioria da doutrina quanto à hipótese da tentativa nos delitos formais ${ }^{35}$ (o que não será objeto de discussão do presente trabalho), o que não resta dúvida e o que importa é a natureza formal do art. 2이, I, da lei supra, sendo tal dispositivo "crime de perigo concreto e direto para o bem jurídico tutelado" ${ }^{36}$,consumando-se com a prática de ato que vise à supressão ou redução do crédito tributário, produzindo-se efeitos permanentes, eis que os objetos mediante os quais foi praticada a fraude conservam sua eficácia ${ }^{37}$.

EISELE, 1998. p. 148.

34 Ibid.

35 Cezar Roberto Bitencourt classifica os delitos formais (em regra) como unissubisistentes, onde o "processo executivo unitário, que não admite fracionamento, coincide temporalmente com a consumação, sendo impossivel, consequentemente, a tentativa". (BITENCOURT, Cezar Roberto. Tratado de direito penal: parte geral. v. 1. 9. ed. São Paulo: Saraiva, 2004. p. 195). Neste mesmo sentido, René Ariel Dotti (2004. p. 328) e Luiz Regis Prado (PRADO, Luiz Regis. Curso de Direito Penal Brasileiro: parte geral. São Paulo: Revista dos Tribunais, 1999. p. 254). Já Eugênio Raúl Zaffaroni e José Henrique Pierangelli entendem que na legislação brasileira todos os crimes admitem tentativa. "Portanto, qualquer crime pode ficar em grau de tentativa, inclusive os crimes de perigo e os denominados 'crimes de pura atividade'. (ZAFFARONI, Eugênio Raúl; PIERANGELLI, José Henrique. Da tentativa: doutrina e jurisprudência. 4. ed. São Paulo: Revista dos Tribunais, 1995. p. 20).

36 SALOMÃO, 2001. p. 210.

37 EISELE, 1998. p. 149. 


\section{A necessidade da prévia decisão definitiva administrativa para a configuração do crime do art. 20, I da Lei 8.137/90}

Com base nas alegações em tela, seria possível a prévia declaração definitiva das autoridades fazendárias da existência do tributo, como elemento normativo do tipo para a configuração do delito do art. 20, I da Lei 8.137/90?

A doutrina em geral e a jurisprudência, no que tange aos crimes penaistributários têm exigido a prévia decisão definitiva administrativa apenas nos crimes materiais e não nos formais, pois segundo Alex Nunes de Figueiredo, o qual entende ser imprescindível o término do procedimento administrativo-fiscal apenas nos crimes materiais, explica que

o lançamento somente se tornará imutável quando o agente passivo da obrigação tributária, após ter sido regularmente notificado, deixa de oferecer a competente defesa, ou recurso administrativo, ou se defendendo, não lograr êxito na instância recursal tendo contra si decisão transitada em julgado no âmbito administrativo; aí sim estará definitivamente constituído o crédito tributário, passando, portanto, a ser exigível. ${ }^{38}$

Em um caso concreto, a 8a Turma do Tribunal da 4ạ Região, de Porto Alegre, tendo como relator do Habeas Corpus no 2004.04.01.051515-4/PR o Desembargador Federal Élcio Pinheiro de Castro, decidiu que na omissão de declaração de valores a Receita Federal, conduta tipificada no art. 2으, I, Lei $8.137 / 90$, não se faz necessário o término do procedimento administrativo para a persecução penal, pois se trata de delito instantâneo, "sendo suficiente para configurar o fato típico a simples constatação de não terem sido declaradas as quantias na época apropriada (crime formal). Assim o tipo penal em comento independe do exaurimento na esfera fiscal, porquanto tal circunstância se afigura irrelevante para efeito de sua caracterização" ${ }^{39}$.

Data máxima vênia, o presente artigo segue de forma contrária aos entendimentos supra mencionados, sendo indubitável o "trânsito em julgado" da esfera administrativa não só para os crimes materiais, mas, também, para os crimes formais previstos no art. 2이 da Lei

ALMEIDA apud. DELMANTO. op. cit.. p. 75.

39 BRASIL. Tribunal Regional Federal (4a Região). Habeas-corpus no 2004.04.01.051515-4/PR, 8a T., Porto Alegre, 16 de fevereiro de 2005. Relator: Élcio Pinheiro de Castro. Diário da Justiça da União, Brasília, DF, Seção 2, n. 36, p. 642, 23 fev. 2005. 
dos Crimes Contra a Ordem Tributária” ${ }^{40}$, visto que o art. 2ํ, I, da lei em comento, está inserido nos delitos tributários, exigindo-se que - no mínimo - para a persecução criminal (investigação policial), tenha a existência do tributo o qual deverá ser "constituído" pela autoridade competente.

Desse modo, para que se possa iniciar uma investigação criminal ou ação penal (quanto aos arts. 10 e 20 da Lei 8.137/90) é preciso - no mínimo - que já exista o tributo, e que este seja devido.

Ademais, admitindo-se o crime em tela como um delito subsidiário (tentado) ${ }^{41}$ do art. 19 , I, da Lei $8.137 / 90$, também é preciso a existência do tributo, visto que a tentativa é a "figura intrincada de um crime. Deve possuir tudo o que caracteriza o crime, menos a consumação" ${ }^{42}$, caso contrário o fato será atípico.

Ainda que assim não fosse, se o elemento subjetivo do tipo do art. 2ㅇ, I, constitui-se no fim especial de eximir-se, total ou parcialmente, de pagamento de créditos tributos, a exemplo do que ocorre nos crimes materiais, se o contribuinte, no delito formal, vier a provar na esfera administrativa (exercendo seus direitos constitucionais) que o tributo não era exigível, não há como subsistir o crime do art. $2^{0^{43}}$, impedindo-se o início até mesmo do inquérito policial, enquanto não declarado pelas autoridades fazendárias a existência do tributo.

Neste mesmo sentido, Hugo de Brito Machado, ao comentar o delito do art. 2으, da lei 8.137/90 afirmou que "mesmo em se tratando de crime formal, como é o tipo previsto no art. 2으, II, da Lei no 8.137/90, tem-se como imprescindível o exaurimento da via administrativa, pois o dolo específico é indispensável à configuração do crime, e não poderá estar presente se não houver um tributo devido" ${ }^{44}$ (grifo nosso), o que se verifica também quanto ao inciso I do delito supra.

O que se verifica in casu é que não há tributo suprimido ou reduzido, quando, repita-se, nem mesmo há instauração de procedimento administrativo a fim de declarar a existência ou não de créditos tributários .

40 DELMANTO, op. cit.. p. 75.

41 Conforme entendimento de Andréas Eisele (1998. p. 148).

42 BITENCOURT, 2004. p. 418.

43 DELMANTO, 1998. p.76.

44 MACHADO, 2002. p. 168,. 
Se não há instauração (ou decisão definitiva) de processo administrativo para apurar suposta supressão ou redução de débito tributário perante as autoridades fazendárias, não existe obrigação tributária exigível ${ }^{45}$.

Neste panorama de incerteza sobre o valor e a própria existência do tributo (como por exemplo, na apreensão de valores na residência do agente), imprescindível à decisão definitiva administrativa do suposto tributo omitido ou não declarado, pois conforme decidiram a "maioria dos ministros do Supremo, o procedimento administrativo em trâmite gera 'estado de incerteza objetiva', que impede a configuração do crime tributário [...]. Em comum, pouco ou nenhum valor probatório é conferido ao procedimento administrativo tributário não encerrado". ${ }^{46}$

A adoção do posicionamento majoritário da inexistência do lançamento definitivo para constatação do delito do art. 2ํㅡ, I, leva a conclusão de que a pendência ou até mesmo a inexistência do procedimento administrativo estão arrimadas em prova particularmente frágil, modelo este incompatível com o estado de incerteza ocasionado pelo procedimento administrativo ainda não concluído, onde muito além do desconhecimento do valor devido, não se sabe sequer se há algo a ser pago ${ }^{47}$ (grifo nosso)

Admitir-se qualquer procedimento criminal (seja inquisitorial ou acusatório) antes da decisão definitiva administrativa "é forma clara de negação do direito à certeza no que concerne à relação jurídica tributária e, assim, negação da supremacia constitucional”48.

Outra questão (de divergência doutrinária) está na grande semelhança entre os dispositivos do art. 1으, I e art. 2으, I, ambos da lei $8.137 / 90$, onde a conduta do primeiro (omitir informação ou prestar declaração falsa) encontra também previsão no art. 2o, I (fazer declaração falsa ou omitir declaração), tipificando-se as "mesmas condutas, mas em artigos diferentes. No art. 1ํㅡ, exigiu a ocorrência da supressão ou redução do tributo; já no art. 2ํ, relevou o resultado, contentando-se tão-somente com a mera conduta." ${ }^{49}$

Segundo Fábio Machado de Almeida Delmanto, "se para a ocorrência do crime material do art. 1ㅇ - cuja pena é mais severa - doutrina e jurisprudência exigem o término do

\footnotetext{
45 PELUSO, Cezar. BRASIL. Supremo Tribunal Federal. Habeas-corpus no 81.611-8/DF. Brasília, DF, 10 de dezembro de 2003. Relator: Min. Sepúlveda Pertence. Diário da Justiça da União, Brasília, 13 maio 2005.

46 PIMENTEL, Débora; DALL'ACQUA, Rodrigo. Procedimento administrativo tributário e medida cautelar no processo penal. Boletim IBCCRIM, v. 12, n. 144, p. 9-10, nov. 2004. p. 9.

47 PIMENTEL; DALL'ACQUA, 2004. p. 9.

48 MACHADO, Hugo de Brito, op. cit. p. 163.

49 DELMANTO, 1998. p. 77.
} 
procedimento administrativo-fiscal, por que não exigi-lo também para a configuração do art. 2으, que é bem menos grave? Haveria total desproporcionalidade e tratamento desigual para condutas que, no fundo, são as mesmas" ${ }^{50}$.

Tanto no ordenamento jurídico brasileiro como no contemporâneo, a aplicação e o entendimento do princípio da proporcionalidade, que deriva das constituições, principalmente na aplicação do direito penal, ganhou relevante importância, sendo que o princípio da proporcionalidade "representa uma especial característica de garantia aos cidadãos, na medida em que impõe sejam as restrições à liberdade individual contrabalançadas com a necessitada tutela a determinados bens jurídicos, e somente confere legitimidade às intervenções que se mostrarem conformes aos seus ditames" ${ }^{51}$.

Diante disso, pode-se concluir que o reconhecimento da necessidade do

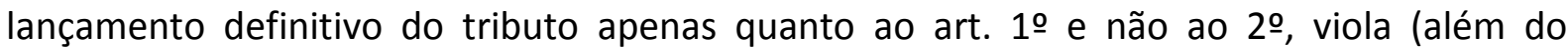
princípio da proporcionalidade) o princípio da igualdade, pois no termos da lição de Rui Stoco, "não basta a igualdade perante a lei, mas ainda é mister a igualdade através da lei" ${ }^{52}$, o que não se verifica neste caso.

Assim, a conduta de fazer declaração falsa ou omitir declaração sobre rendas, bens ou fatos, ou empregar outra fraude para eximir-se de pagamento de tributo (art. $2^{\circ}$, I) apenas será típica diante da existência material de fato que se ajuste ao dever de declarar ${ }^{53}$, o que somente poderá ser constatado após o lançamento definitivo da autoridade fazendária, visto que até então inexiste o "tributo", inocorrendo justa causa para a persecutio criminis.

\section{Conclusão}

Verificou-se no presente estudo que o art. 2으, I, da lei já referida possui a mesma natureza jurídica do crime do art. 1으, ou seja, é um delito penal tributário, sendo que para sua configuração se exige - no mínimo - a existência do tributo.

Ibid.

51 GOMES, Mariângela Gama de Magalhães. O princípio da proporcionalidade no direito penal. São Paulo: Ed. Revista dos Tribunais, 2003. p. 59.

52 FRANCO, Alberto Silva; STOCO, Rui (Coord.). Leis penais especiais e sua interpretação jurisprudencial. 7. ed. São Paulo: Ed. Revista dos Tribunais, 2001. p. 604.

53 DELMANTO, 1998. p. 78. 
Conforme o estabelecido pela Carta Magna, o direito constitucional garante a todos o contraditório e a ampla defesa não somente no âmbito judicial, mas também no procedimento administrativo (art. 5ํㅡ, LV), bem como ninguém será privado da sua liberdade sem o devido processo legal. Isso também vale para o contribuinte que discute o débito tributário na via administrativa.

Valendo-se pelo princípio da igualdade e da proporcionalidade, como a existência do tributo devido é pressuposto para a configuração do crime dos arts. 1ㅇ e 2 , I da lei 8.137/90, pouco importando se o delito é material ou formal, imperioso se faz uma decisão definitiva administrativa acerca da exigibilidade do tributo, antes mesmo da instauração de inquérito policial, pois conforme já decidido pelo Supremo Tribunal Federal, a competência para dizer da existência do tributo é exclusiva das autoridades fazendárias.

Ante o exposto, tratando-se o delito descrito no art. 20, I da Lei № 8.137/90, crime de natureza formal, sendo neste "imprescindível a existência de um tributo devido, sem o qual o dolo específico não é possível" ${ }^{54}$, imperioso a necessidade da prévia decisão definitiva administrativa acerca do crédito tributário, pois tal condição figura-se como um elemento normativo do tipo em tela, sem o qual não existirá obrigação tributária exigível e conseqüentemente inexistirá delito contra a Ordem Tributária.

\section{Referências}

ALVARENGA, Aristides Junqueira. Crimes contra a ordem tributária. In: MARTINS, Ives Granda (Coord.). Crimes contra a ordem tributária. São Paulo: Ed. Revista dos Tribunais, 1995.

BITENCOURT, Cezar Roberto. Tratado de direito penal: parte geral. 9. ed. São Paulo: Saraiva, 2004. v. 1.

BITTAR, Walter Barbosa. As condições objetivas de punibilidade e as causas pessoais de exclusão da pena. Rio de Janeiro: Lúmen Júris, 2004.

BRASIL. Supremo Tribunal Federal. Habeas-corpus $\mathrm{n}^{\circ}$ 75.945-2-DF, 1a T., Brasília, DF, 2 dezembro de 1997. Relator: Min. Sepúlveda Pertence. Diário da Justiça da União, Brasília, 13 fev. 1998.

54 MACHADO apud. DELMANDO, op. cit.., p. 77. 
BRASIL. Supremo Tribunal Federal. Habeas-corpus n ${ }^{\circ}$ 81.611. Brasília, DF, 10 de dezembro de 2003. Relator: Min. Sepúlveda Pertence. Diário da Justiça da União, Brasília, 13 maio 2005.

BRASIL. Supremo Tribunal Federal. Habeas-corpus n 83.414-1, da 1aㅗ., Brasília, DF, 2 de março de 2004. Relator: Min. Joaquim Barbosa. Diário da Justiça da União, Brasília, 23 abr. 2004.

BRASIL. Supremo Tribunal Federal. Habeas-corpus no 81.611-8/DF. Brasília, DF, 10 de dezembro de 2003. Relator: Min. Sepúlveda Pertence. Diário da Justiça da União, Brasília, 13 maio 2005.

BRASIL. Tribunal Regional Federal (4a Região). Habeas-corpus no 2004.04.01.051515-4/PR, 8a T., Porto Alegre, 16 de fevereiro de 2005. Relator: Élcio Pinheiro de Castro. Diário da Justiça da União, Brasília, DF, Seção 2, n. 36, p. 642, 23 fev. 2005.

CORRÊA, Antônio. Dos crimes contra a ordem tributária: comentários à Lei n. 8.137, de 2712-1990. São Paulo: Saraiva, 1994.

COSTA JR., Paulo José da; DENARI, Zelmo. Infrações tributárias e delitos fiscais. São Paulo: Saraiva, 1995.

DELMANTO, Fabio Machado de Almeida. O término do processo administrtivo-fiscal como condição da ação penal nos crimes contra a ordem tributária. Revista Brasileira de Ciências Criminais, São Paulo, v. 6, n. 22, p. 63-79, abr./jun. 1998.

DOTTI, René Ariel. Curso de direito penal: parte geral. 2. ed. rev., atual. e ampl. Rio de Janeiro: Forense, 2004.

EISELE, Andréas. Crimes contra a ordem tributária. São Paulo: Dialética, 1998.

FRANCO, Alberto Silva; STOCO, Rui (Coord.). Leis penais especiais e sua interpretação jurisprudencial. 7. ed. rev., atual. e ampl. São Paulo: Ed. Revista dos Tribunais, 2001. 2 v.

GOMES, Luiz Flávio. Direito penal: parte geral: teoria constitucionalista do delito. São Paulo: Ed. Revista dos Tribunais, 2004.

GOMES, Mariângela Gama de Magalhães. O princípio da proporcionalidade no direito penal. São Paulo: Ed. Revista dos Tribunais, 2003.

MACHADO, Hugo de Brito. Crimes contra a ordem tributária. In: MARTINS, Ives Granda (Coord.). Crimes contra a ordem tributária. São Paulo: Ed. Revista dos Tribunais, 1995. 
MACHADO, Hugo de Brito. Estudos de direito penal tributário. São Paulo: Atlas, 2002.

PIMENTEL, Débora; DALL'ACQUA, Rodrigo. Procedimento administrativo tributário e medida cautelar no processo penal. Boletim IBCCRIM, ano 12, n. 144, p. 9-10, nov. 2004.

PITOMBO, Antônio Sergio Altieri de Moraes. O que não nos ensinaram sobre crime tributário. Boletim IBCCRIM, v. 12, n. 147, p. 4-5, fev. 2005.

PRADO, Luiz Regis. Curso de Direito Penal Brasileiro: parte geral. São Paulo: Ed. Revista dos Tribunais, 1999.

SAAD, Marta; MALAN, Diogo. Crimes contra a ordem tributária e a portaria SRF 326/05: novo esforço para restaurar a lógica do sistema. Boletim IBCCRIM, v. 13, n. 150, p. 11-12, maio 2005.

SALOMÃO, Heloisa Estellita. A tutela penal e as obrigações tributárias na Constituição Federal. São Paulo: Ed. Revista dos Tribunais, 2001.

SCHOLZ, Leônidas Ribeiro. A criminalidade contra a ordem tributária no universo do direito econômico. Revista Brasileira de Ciências Criminais, São Paulo, v. 6, n. 30, p. 95-107, abr./jun. 2000.

SOUZA, Nelson Bernardes de. Crimes contra a ordem tributária e processo administrativo. Revista Brasileira de Ciências Criminais, São Paulo, v. 5, n. 18, p. 93-101, abr./jun. 1997.

STOCO, Rui. Sonegação fiscal temas controvertidos. Revista dos Tribunais, São Paulo, v. 84, n. 713, p. 315-327, mar. 1995.

TÓRTIMA, Jose Carlos. O objeto da tutela jurídica nos crimes fiscais. In: SALOMÃO, Heloisa Estelita (Coord.). Direito penal empresarial. São Paulo: Dialética, 2001.

ZAFFARONI, Eugênio Raúl; PIERANGELLI, José Henrique. Da tentativa: doutrina e jurisprudência. 4. ed. rev. e atual. São Paulo: Ed. Revista dos Tribunais, 1995. 
Revista de DiReito Público, LondRINA, v. 1, N. 3, P. 153-168, Set./dez. 2006. 